\title{
Trypanosoma Cruzi Experimental Infection and COVID-19: Similar Cardiovascular Syndrome?
}

\author{
André Secundino Abbagliato ${ }^{2}$, Maria Inês Doria Rossi ${ }^{2}$ and Gabriel Melo de Oliveira ${ }^{1 *}$ \\ ${ }^{1}$ Cell Biology Laboratory, Oswaldo Cruz Institute, Brazil \\ ${ }^{2}$ Institute of Science and Technology in Biomodels. Oswaldo Cruz Fundation, Brazil
}

*Corresponding author: Gabriel Oliveira, Cell Biology Laboratory, Oswaldo Cruz Institute, Oswaldo Cruz Fundation, Av. Brasil, 4365 - Rio de Janeiro, Brasil.

To Cite This Article: André Secundino Abbagliato, Maria Inês Doria Rossi, Gabriel Melo de Oliveira. Trypanosoma Cruzi Experimental Infection and COVID-19: Similar Cardiovascular Syndrome?. Am J Biomed Sci \& Res. 2021 - 13(1). AJBSR.MS.ID.001832.

DOI: 10.34297/AJBSR.2021.13.001832.

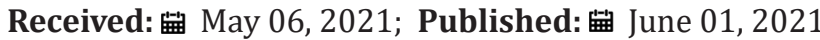

\begin{abstract}
Dr. Carlos Chagas, in 1909, published his notable discovery, a new pathology denominated Chagas disease. He was able to identify: etiologic agent, the protozoan Trypanosoma cruzi, its biological cycle and your pathogenesis: etiologic agent, the protozoan T. cruzi its biological cycle and your pathogenesis. However, to date, there is still no vaccine or effective treatment for the symptomatic chronic phase. In 2019, a new Severe Acute Respiratory Syndrome, promoted by a member of the Coronavirus family, emerged in Wuhan (China province), whose origin has not yet been totally elucidate. SARS-Cov-2 or COVID-19 is characterize by high transmissibility and high morbidity. Thus, in 2020 it became a global pandemic. Highlights into similarities between a neglected disease, which affects 40.000 new cases per year and intense research for a vaccine and treatment using experimental models and severe COVID-19 infection, with millions of victims, by evolution to cardiovascular disturbance, mainly through its target point to ACE2 enzyme. To compare acute T. cruzi experimental infection in mice, the cardiorenal axis involvement and suggest possible common points to research about serious course of the COVID- 19 infection and cardiovascular involvement.
\end{abstract}

Keywords: Trypanosoma cruzi; Murine model; Cardiovascular; COVID-19

\section{Introduction}

\section{Chagas disease}

Trypanosoma Infection: Dr. Carlos Chagas, in 1909, published his notable discovery, a new pathology denominated Chagas disease [1]. An unprecedented medicine feat, he was able to identify: etiologic agent, the protozoan Trypanosoma cruzi, its biological cycle and your pathogenesis [2]. This disease affects a large part of the world population in a situation of social vulnerability, considered a neglected disease (NTDs) [3]. Actions to control the endemic infection of T. cruzi were perform, such as the eradication of its invertebrate vector (by Triatoma infestans) and required testing in blood donnors [4-6]. As described by Moncayo \& Silveira (2009) the Latin Amerca incidence of Chagas disease has dropped from 700.00 to 40.000 new cases per year [6]. Death number per year is between 45.000 to 12.500 patients deaths6. The main route of transmission is still vector through the bite of insects popularly called "Barbeiro", "Chupança” or "Vinhuca”. However, its infectious form, the metacyclic trypomastigote, can be found in natural foods, such as açaí, bacaba and fruit pulps, increasing its risk of transmission through oral contamination $[7,8]$. The classic pathogenesis has two distinct phases: the acute phase, characterized by mild, non-specific symptoms [6-8], in which approximately $10 \%$ of all patients have severe myocarditis, with $90 \%$ of these having an unfavorable prognosis [9]. Approximately 20 to 30\% of infected patients will develop the symptomatic chronic phase, which is the most severe, with severe cardiac involvement due to chronic myocardiopathy and the presence of dilations in digestive organs, such as the megaesophagus and megacolon $[3,10]$. According Lizzeti et, al., (2019) he only drugs available for the treatment of T. cruzi infection are nifurtimox and benznidazole [10]. However, currently benznidazole is the most widely used drug, however it is not effective during the chronic symptomatic phase of the disease 
and can promote serious side effects, especially in infants $[10,11]$. Moreover, to date, no other drug has had a trypanocidal efficacy similar to benznidazole and we still do not have a vaccine, despite more than 100 years of disease research [11-13].

The experimental mouse model, depending on the binomial of infection, mouse lineage \& parasite strain becomes more susceptible or resistant to infection14. However, it allows the investigation of several aspects of the pathogenesis of T. cruzi infection in a relatively short period of time. In addition, due to its genetic homology to the human being, several approaches can be clarified, such as immunological response, cardiac remodeling and preclinical tests for the evaluation of experimental chemotherapies in the search for an effective compound for the treatment of chagasic patients $[14,15]$.

\section{Severe Acute Respiratory Syndrome Coronavi-}

\section{rus-2}

\section{COVID-19:}

In accordance with the excellent review by Youki et al. [16] during 2019, a new Severe Acute Respiratory Syndrome, promoted by a member of the Coronavirus family, emerged in Wuhan (China province), whose origin has not yet been totally elucidate, probably zoonotic way transmission. SARS-Cov-2 or COVID-19 is characterize by high transmissibility and high morbidity. Thus, in 2020 it became a global pandemic, after virus modifications, was observed humanhuman infection [16-18].

The classic symptoms of COVID-19 are characterized by the involvement of the respiratory system, from asymptomatic to severe cases 19. There is fever, dry and prolonged cough, difficulty breathing and pneumonia [19-21]. However, the mechanism of infection of the virus in the body occurs through an enzyme called angiotensin-converting enzyme type 2, or ACE2 (the spike for COVID-19 also bound to ACE2), present in lung tissue [21-22]. However, ACE2 is also found in several other tissues, mainly the endothelium of the lung, heart, ileum, kidney and bladder [22,23]. Thus, it is currently believed that the evolution of respiratory cases to death due to cardiovascular shock caused by thromboembolism is associated with the connection between COVID-19 and endothelial ACE2 expression, however it is still not completely elucidated, but probably occurs microvascular compromise [24,25]. The prognosis may be even more unfavorable, because in some patients, this virus can also affect the central nervous system (CNS) [24,26].

\section{State-of-Art}

The preclinical study of T. cruzi infection, since 1909, demonstrated a diverse use of biomodels, such as mice, rats, dogs and opossums [25]. However, with the refinement of techniques and the use of transgenic models using the mouse model, it became possible, especially in Outbred Stock mice, to evaluate, in a short period of time, the evolution of the acute phase, the symptoms in the chronic phase and the effectiveness of experimental compounds, more closely the possibility of translating the results to the patient with reliability [17]. However, experimental murine infection, in the acute and chronic phase, has always had a primary focus on cardiac involvement and the, still unknown, mechanism to which asymptomatic patients develop Chagas' heart disease [27]. Experimental infection by COVID-19 still requires unconventional models in the science of laboratory animals, such as ferrets and humanized mice Taconic and Jackson Labs developed: Tbd, expressing human ACE2; Ace2 knockout, ACE2 Low expression and K18-hACE2- ACE2 expression; Tmprss2 Knockout; Stat1 knockout. Standards murine lineages as Balbc, C57Bl6 agedependent develop clinical illnesses, including irregular interstitial pneumonia [28]. The conception of this review was based on the hypothesis of possible similarities between the use and evaluation of the experimental mouse biomodel in both infections, both by the parasite and the viral. We are convinced that, among striking differences, the use of the mouse biomodel in both infections is not contemplating the elements of the complex network associated between the various biological systems, such as only the cardiac involvement in T. cruzi infection and the involvement of the lung in the case of COVID-19.

\section{Compilation and Reflections}

According to Yuki et. Al. [16] the severity criteria for COVID-19 infection are determined by

1. Asymptomatic COVID: Without any clinical symptoms imaging diagnosis normal.

2. Mild Acute: Uupper respiratory tract syntomd as: fever, fatigue, myalgia, cough, sore throat, runny nose, sneezing or digestive symptoms.

3. Moderate Respiratory: with fever, cough, hypoxemia and imaging chest test positive.

4. Severe Respiratory: severe hypoxemia

5. Systemic complications: severe pneumonia, heart failure, cardiovascular shock; encephalopathy and acute kidney injury [16].

In the experimental study of acute T. cruzi infection in mice one of the most susceptible binomials is the Balbc lineage \& Y strain infection. It promotes high mortality due to the severity of acute myocarditis and is a widely used model for assessing the immune response. Our research group demonstrated that before the evolution of acute myocarditis there is, even during the presence of parasites in the blood, a marked, but transient, acute kidney injury 
$[29,30]$. We evaluated, in vitro, the several types infection of renal cells infected by T. cruzi and observed that there was an inverse relationship, mainly in mesangial cells, that the presence of the parasite, not necessarily replicating in renal tissue, increased the oxide nitric levels in the cell culture supernatant, as well as cytokine TNF [30]. At the cellular level, this may be one of the explanations for the early acute kidney injury and its consequences, such as the drop in blood pressure and the perception of the justaglomerular apparatus (immunocomplex deposition) [31], activating the reninangiotensin-aldosterone system (RAAS).

The activated RAAS can perform several systemic effects, such as vasoconstriction, in this case, as a positive feedback to the perception of a decreased in cardiovascular pressure, endothelial and cardiac muscle remodeling [32]. Our in vivo investigation has shown that the use of multi-stage RAAS blockers (losartan, captopril and spironolactone), directly interfere in increasing the animals' survival, which suggests that not only is acute myocarditis the cause of death of the animals, but rather the influence of the renal-cardio axis associated with the severity of the acute inflammatory response in the heart muscle [33]. Interestingly, the use of spironolactone significantly minimized the mortality of mice infected with T. cruzi [33]. Our theory, still in studies, would be that the parasite, inside the organism, promotes some type of toxicity, ancient manuscripts describe the possibility of chagastoxin $[34,35]$. Thus, we would have an association between acute kidney injury, histopathological analysis showed glomerular IgM deposits [29], changes in the cardiovascular and endothelial system, myocardial inflammatory response due to parasitic multiplication, evolution to cardiogenic shock and death of the animal [36]. Spironolactone suggests minimizing the effects of this possible parasite endo or exotoxin, decreased vasodilation, or loss of elasticity of the endothelium, balancing blood pressure in the vessels and avoiding cardiogenic shock [37,38]. Melnikov et al. [39] described that, during different phases, T. cruzi infection can be observed in lungs. The parasite presence were were accompanied by mononuclear inflammatory infiltrate promoted compromised in the alveoli walls and lung hemorrhage $[39,40]$.

Ingraham et al. [41] suggest RAAS inhibition decreases COVID-19 lung injury and improves survival, while simultaneously decreasing viral load in animal models with viral infections that utilize the ACE2 receptor [38]. Experimental acute T. cruzi infection, showed that RAAS-block throught use (before infection) of multistage RAAS blockers (losartan, captopril and spironolactone), directly interfere in increasing the animals' survival, which suggests that not only is acute myocarditis the cause of death of the animals, but rather the influence of the renal-cardio axis associated with the severity of the acute inflammatory response in the heart muscle [33]. So, when we compare both infections and the serious stage of
COVID-19, it suggests that the key mechanism we should be looking at would be the modulation of the RAAS. Mainly using an initial system blocker such as Aliskiren that blocks Renin's conversion [41].

\section{Conclusions}

In this review, we do not intend to compare or suggest translate of the infection and the relationship between the evolution and severity of COVID-19 with the experimental T. cruzi infection. Our goal is for our observation and knowledge of both infections, and the long experience in the development of the science of laboratory animals, to propose key points that can be used by other research groups in the search for the mitigation of this terrible pandemic and in some way, we are prepared for others broad-spectrum viral, bacterial, parasitic infections that could become a global public health problem [42].

We believe, in addition to physical structures, personal training and an increase in the technological and scientific political development, that at the laboratory level, using animals for scientific purposes, some chalenges are important at this moment:

1. Development of a murine model, a mouse biomodel, capable of developing in house facilities the COVID-19 infection in a similar way to critically ill patients.

2. Refine biomodel assessment techniques, primarily by using equipment that enables the assessment of environmental and controlled transmissibility of the virus, not only susceptibility to intranasal inoculations.

3. Use techniques and procedures that are closest to those used by humans, especially at the critical and systemic level of infection, such as endothelial changes, thromboembolism and pulmonary embolism.

4. Possibility of quickly, reproducibly and reliably testing experimental therapies, acute and chronic toxicity of new compounds (or repositioning of drugs) and vaccines.

Finally, we would like to affirm that the identification of kidney injury in mice infected with T. cruzi during the acute phase was relevant because, in many moments, we "close" the focus on an organ or system and as the infection by COVID-19, we must observe the genesis of the pathology in a complex interconnected system, because in both cases, the infection will progress to cardiovascular shock and multiple organ failure.

Sharing one of our hypotheses, we believe that, as already observed, patients infected in the acute phase are also presenting with acute kidney injury. Would there be a possibility that the cardio-renal axis is involved in 20 to $30 \%$ of the population that has 
severe cardiac symptoms in the chronic phase of Chagas disease? So, research on the cardiovascular system in critically ill patients infected with COVID-19, can be a field of study, primarily to save the lives of these patients, but used to increase knowledge of the genesis of cardiovascular syndromes, such as thrombosis, strokes and others.

\section{References}

1. Chagas C (1909) Nova especie morbida do homem, produzida por um Trypanozoma (Trypanozoma cruzi): nota prévia. Brazil-Medico 16: 161171.

2. Chagas C (1909) Nova tripanozomiase humana: estudos sobre a morfolojia e o ciclo evolutivo do Schizotrypanum cruzi n. gen., n. sp., ajente etiolojico de nova entidade morbida do homem. Memórias do Instituto Oswaldo Cruz 2: 159-218.

3. World Health Organization (WHO) (2017) Integrating neglected tropical diseases into global health and development. Fourth WHO report on neglected tropical diseases. World Health Organization Geneva.

4. Dias JC, Prata A, Correia D (2008) Problems and perspectives for Chagas disease control: in search of a realistic analysis. Rev Soc Bras Med Trop 41(2): 193-196.

5. Coura JR, Borges-Pereira J (2010) Chagas disease: 100 years after its discovery. A systemic review. Acta Trop 115(1-2): 5-13.

6. Moncayo A, Silveira AC (2009) Current epidemiological trends for Chagas disease in Latin America and future challenges in epidemiology, surveillance and health policy. Mem Inst Oswaldo Cruz 104 Suppl 1: 1730.

7. Coura JR (2006) Transmission of chagasic infection by oral route in the natural history of Chagas' disease. Rev Soc Bras Med Trop 39 Suppl 3: 113-117.

8. Beltrao B, Cerroni P, Freitas DR, Pinto AY, Valente V C, et al. (2009) Investigation of two outbreaks of suspected oral transmission of acute Chagas disease in the Amazon region, Para State, Brazil, in 2007. Trop Doct 39(4): 231-232.

9. Parada H, Carrasco A, Anez N, Fuenmayor C, Inglessis I (1997) Cardiac involvement is a constant finding in acute Chagas' disease: a clinical, parasitological and histopathological study. Int J Cardiol 60(1): 49-54.

10. Lescure FX, Le Loup G, Freilij H, Develoux M, Paris L, et al. (2010) Chagas disease: changes in knowledge and management. Lancet Infect Dis 10(8): 556-570.

11. Meymandi S, Hernandez S, Park DR, Sanchez C (2018) Treatment of Chagas disease in the United States. Curr Treat Options Infect Dis 10(3): 373-388.

12. CDC (2019) Antiparasitic Treatment. Centers for Disease Control and Prevention.

13. Lizette E, Rios JC, Vázquez Chagoyán AM, Paola Zago N (2019) Immunity and vaccine development efforts against Trypanosoma cruzi. Acta Tropica 200: 105-168.

14. Moreno M, D'ávila DA, Silva MN, Lúcia Mc Galvão, Andrea M Macedo, et al. (2010) Trypanosoma cruzi benznidazole susceptibility in vitro does not predict the therapeutic outcome of human Chagas disease. Mem Inst Oswaldo Cruz 105(7): 918-924.

15. Lenzi H, Oliveira D, Lima M, Gattass CR (1996) Trypanosoma cruzi: paninfectivity of CL strain during murine acute infection. Exp Parasitol 84(1): 16-27.

16. Yuki K, Fujiogi M, Koutsogiannaki S (2020) COVID-19 pathophysiology: A review. Clinical Immunology 215: 108-227.
17. Ksiazek TG, Erdman D, Goldsmith CS, Zaki SR, Peret T, et al. (2003) A novel coronavirus associated with severe acute respiratory syndrome. N Engl J Med 348(20): 1953-1966.

18. Li Q, Guan X, Wu P, Wang X, Zhou L, et al. (2020) Early transmission dynamics in Wuhan, China, of Novel Coronavirus-infected pneumonia. N Engl J Med 382: 1199-1207.

19. Shi H, Han X, Jiang N, Cao Y, Alwalid O, et al. (2020) Radiological findings from 81 patients with COVID-19 pneumonia in Wuhan, China: a descriptive study. Lancet Infect Dis 20: 425-434.

20. Chen Y, Guo Y, Pan Y, Zhao ZJ (2020) Structure analysis of the receptor binding of 2019-nCoV. Biochemical and Biophysical Research Communications 525(1): 135-140.

21. Alexandra C Walls, Young-Jun Park, M Alejandra Tortorici, Abigail Wall, Andrew T McGuire, et al. (2020) Structure, function, and antigenicity of the SARS-CoV-2 spike glycoprotein. Cell 181(2): 281-292.

22. Letko M, Marzi A, Munster V (2020) Functional assessment of cell entry and receptor usage for SARS-CoV-2 and other lineage B betacoronaviruses. Nat Microbiol 5(4): 562-569.

23. Zeng H, Pappas C, Belser JA, Houser KV, Zhong W, et al. (2012) Human pulmonary microvascular endothelial cells support productive replication of highly pathogenic avian influenza viruses: possible involvement in the pathogenesis of human H5N1 virus infection. J Virol 86(2): 667-678.

24. Wang M, Hao H, Leeper NJ, Zhu LC, Early Career (2018) Thrombotic regulation from the endothelial cell perspectives. Arterioscler Thromb Vasc Biol 38(6): e90-e95.

25. Lovren F, Pan Y, Quan A, Teoh H, Wang G, et al. (2008) Angiotensin converting enzyme- 2 confers endothelial protection and attenuates atherosclerosis. Am J Physiol Heart Circ Physiol 295(4): H1377-H1384.

26. Sluime JC, Gasc JM, Hamming I, Van Goor H, Michaud A, et al. (2008) Angiotensin-converting enzyme 2 (ACE2) expression and activity in human carotid atherosclerotic lesions. J Pathol 215(3): 273-279.

27. Zou X, Chen K, Zou J, Han P, Hao J, et al. (2020) Single-cell RNA-seq data analysis on the receptor ACE2 expression reveals the potential risk of different human organs vulnerable to $2019-\mathrm{nCoV}$ infection. Front Med 14(2): 185-192.

28. Chagas C (1909) Trabalho do Instituto de Manguinhos sobre uma nova trypanosomiase humana, pelo dr. Carlos Chagas, assistente do Instituto. Annaes da Academia de Medicina do Rio de Janeiro 75: 188-190.

29. Oliveira GM (2020) Laboratory Mouse \& COVID-19 Research. OAJBS 2: 34-37.

30. De Oliveira GM, Da Silva TM, Batista WS, Franco M, Schor N (2009) Acute Trypanosoma cruzi experimental infection induced renal ischemic/ reperfusion lesion in mice. Parasitol Res 106: 111-120.

31. De Oliveira GM, Yoshida N, Higa EM, Shenkman S, Alves M, et al. (2011) Induction of proinflammatory cytokines and nitric oxide by Trypanosoma cruzi in renal cells. Parasitol Res 109(2): 483-491.

32. Oliveira GM, Masuda MO, Rocha NN, Schor N, Hooper CS, et al. (2009) Absence of Fas-L Aggravates Renal Injury in Acute Trypanosoma Cruzi Infection. Mem Inst Oswaldo Cruz 104(8): 1063-1071.

33. Ramires JA, Salemi V, Ianni B, Fernandes F, Martins DG, et al. (2006) Aldosterone antagonism in an inflammatory state: evidence for myocardial protection. J Renin Angiotensin Aldosterone Syst 7(3): 162167.

34. Chumbinho C, Batista W, Oliveira GM (2012) Influence of the cardiorenal axis in experimental T.cruzi infection. Journal of Experimental and Integrative Medicine 3: 123-127. 
35. Seneca H (1969) Experimental toxaemia in mice due to chagastoxin. Trans R Soc Trop Med Hyg 63(4): 535-539.

36. Seneca H, Peer P (1966) Immuno-biological properties of chagastoxin (lipopolysaccharide). Trans R Soc Trop Med Hyg 60(5): 610-620.

37. Silva DR, Castro SL, Alves MC, Batista Wda S, Oliveira GM (2012) Acute experimental Trypanosoma cruzi infection: establishing a murine mode that utilises non-invasive measurements of disease parameters. Mem Inst Oswaldo Cruz 107(2): 211-216.

38. Lemos JR, Rodrigues WF, Miguel CB, Parreira RC, Miguel RB, et al. (2013) Influence of Parasite Load on Renal Function in Mice Acutely Infected With Trypanosoma Cruzi. PLoS One 8(8): e71772.

39. Melnikov VG, Velasco FF, Espinoza Gómez F, Rodríguez FG, Dobrovinskaya OR (2005) Pathologic changes in lungs caused by Mexican isolates of Trypanosoma cruzi in the acute phase of infection in mice. Am J Trop Med Hyg 73(2): 301-306
40. Bittencourt AL, Rodrigues de Freitas LA, Galvão de Araujo MO, Jácomo K (1981) Pneumonitis in congenital Chagas' disease. A study of ten cases. Am J Trop Med Hyg 30(1): 38-42.

41. Ingraham NE, Barakat AG, Reilkoff R, Tamara Bezdicek, Timothy Schacker, et al. (2020) Understanding the Renin-Angiotensin-Aldosterone-SARSCoV-Axis: A Comprehensive Review. Eur Respir J 56(1): 2000912.

42. Oliveira LRC, Picka MCM, Nicolete VC, Calvi SA, Marcondes-Machado J 92012) Organ tropism during the acute and chronic phases of Trypanosoma cruzi infection in BALB/c mice. J Ven Anim and Toxins Trop Diseases 18(1): 34-43. 